\title{
Criterion validity and user acceptability of a CD-ROM-mediated food record for measuring fruit and vegetable consumption among black adolescents
}

\author{
Jennifer Di Noia ${ }^{1,2, *}$ and Isobel R Contento ${ }^{3}$ \\ ${ }^{1}$ Columbia University School of Social Work, New York, NY 10027, USA: ${ }^{2}$ Intersystems Incorporated, Roxbury, \\ CT 06783, USA: ${ }^{3}$ Teacher's College, Columbia University, New York, NY 10027, USA
}

Submitted 26 January 2007: Accepted 24 November 2007: First published online 26 February 2008

\begin{abstract}
Objectives: To determine the criterion validity and user acceptability of the Healthy Eating Self-Monitoring Tool (HEST), a CD-ROM-mediated food record for measuring fruit and vegetable consumption among economically disadvantaged black adolescents.

Design: Item intakes, daily intake measures of fruit, vegetables and juices, and daily and total fruit and vegetable intake assessed with the HEST over a $3 \mathrm{~d}$ interval were compared with observed intake using Spearman correlations and Wilcoxon signed ranks tests. Mean ratings of participants' interest in, enjoyment of and likelihood of recommending the HEST to peers were compared with an a priori criterion rating for establishing user acceptability of the HEST.

Setting: Youth services agencies in New York City.

Subjects: Eighty-nine black adolescents aged 11 to 14 years.

Results: Spearman correlations were significant for $67 \%$ of items, for daily intake measures of fruit (days 1 and 3), vegetables and juices (days 1 and 2), and for fruit and vegetable intake (all three days). Wilcoxon signed ranks tests found nonsignificant intake differences for $78 \%$ of these items, for daily intake measures of fruit and vegetables, and for fruit and vegetable intake (days 2 and 3). HESTrecorded $3 \mathrm{~d}$ intake of 14.65 servings was significantly correlated with and did not differ significantly from observed $3 \mathrm{~d}$ intake of $15 \cdot 21$ servings. Youths' HEST-recorded intake was accurate to within 0.56 of a serving of their observed intake. Mean ratings of the HEST were above the criterion rating across user acceptability dimensions assessed.

Conclusions: The HEST is a promising food record approach that is acceptable to youths.
\end{abstract}

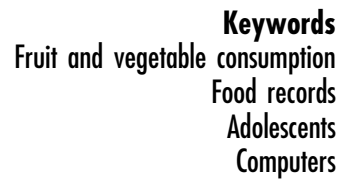

Commonly used approaches for quantifying adolescent dietary intake include the food record, $24 \mathrm{~h}$ recall and $\mathrm{FFQ}^{(1)}$. In the food record approach, respondents identify foods and beverages and the amounts consumed of each, meal-by-meal, over a pre-specified period, typically 3 to $7 \mathrm{~d}^{(2,3)}$. Because foods are recorded as they are consumed, this approach has the potential to provide quantitatively accurate dietary intake data for the recording period, the problem of omitting foods is reduced, and amounts of food consumed may be more accurately recalled than if the respondent was recalling amounts eaten previously ${ }^{(2)}$. Despite these strengths, studies examining the performance of alternative forms of food records are limited ${ }^{(4)}$.

The Healthy Eating Self-Monitoring Tool (HEST) is a fully developed version of a nine-item, CD-ROM-mediated, prototype food record for measuring fruit and vegetable consumption among economically disadvantaged black adolescents $^{(5)}$. In an initial validation study, significant correlations were found between observed and HEST-recorded item intakes measured over the course of a single day ${ }^{(5)}$. Promising results from the research led to the development of the measure that is the focus of the present study.

The prototype measure was expanded to include additional foods and juices and depict items according to a variety of preparation methods. A tutorial on using the HEST and estimating food and juice portions was added. To allow for the recording of foods and juices not represented in the measure, a write-in option was developed.

The purposes of the present study were to determine whether economically disadvantaged black adolescents were able to accurately record their fruit and vegetable intake using the HEST over an interval of three consecutive 
days, and to examine the extent to which youths found the program interesting, enjoyable and worth recommending to peers.

\section{Materials and methods}

\section{Participants}

Eighty-nine black adolescents ( $52 \%$ female) with a mean age of 12 years took part in the study. Participants were recruited through summer camps offered at youth services agencies in New York City. The selected agencies served a predominantly black adolescent population, had on-site computing facilities, and were located in communities in which $20 \%$ or more of households reported family incomes below Federal poverty thresholds in $2000^{(6)}$. Following Institutional Review Board approval, eligible adolescents who expressed interest in the study provided written assent and obtained informed written consent from a parent or guardian.

\section{Direct observation of intake}

Participants were served breakfast, lunch and dinner at participating sites over an interval of three consecutive days. At each meal, youths were given a tray with three 1-serving units of fruit, vegetable and juice items. All youths were served the same fruit, vegetables and juices. Participants were then offered a variety of main course options. This approach was used to increase the likelihood of obtaining multiple measurements of the foods and juices studied. The selection of foods and juices was based on food frequency data obtained in earlier research ${ }^{(5)}$. To determine whether participants were able to accurately record their intake using the HEST write-in option, on the second day youths were served a vegetable (artichoke hearts) at lunch that was not represented in the HEST.

Pairs of trained staff prepared and served meals. Because meals and HEST assessments occurred at different locations within each site, one member of the pair remained present at meals to observe the amounts of foods and juices youths left after eating using the plate-waste-byvisual-estimate method ${ }^{(7)}$. The amounts consumed of each item were recorded on a form that included the following response options: $0, \frac{1}{4}, \frac{1}{2}, \frac{3}{4}$ and 1 . The other staff member supervised HEST assessment sessions.

\section{HEST-recorded intake}

Following meals, youths recorded their intake of fruit, vegetables and juices using the HEST. As youths arrived to complete the HEST, the staff member helped them get situated and instructed them to raise their hands if at any time during the session they required assistance. Because the HEST is designed for self-administration, the assistance was limited to helping youths access and advance through the HEST screens; material guidance was neither offered nor solicited. After completing HEST entries for dinner on the third day, youths were administered a brief feedback form that queried their interest in, enjoyment of and likelihood of recommending the HEST to peers. Youths rated the HEST along each dimension using 5 -point scales with response options that ranged from 1 (not at all) to 5 (a great deal).

The HEST uses digital images, sound and text to gather fruit and vegetable intake data, and is designed to quantify intake in relation to $5 \mathrm{~A}$ Day for Better Health Program criteria $^{(8)}$. Instituted by the National Cancer Institute, the $5 \mathrm{~A}$ Day for Better Health Program encourages Americans to eat five or more daily servings of fruit and vegetables. One serving is defined as 1 medium fruit or $\frac{1}{2}$ cup of small or cut-up fruit; $\frac{3}{4}$ cup of $100 \%$ fruit juice; $\frac{1}{4}$ cup of dried fruit; $\frac{1}{2}$ cup of raw or cooked vegetables; 1 cup of raw leafy vegetables; or $\frac{1}{2}$ cup of cooked beans or peas. As users complete entries for food and juice items, the HEST quantifies their intake in serving units and saves this information, along with a unique user identifier, in a spreadsheet-formatted output file. The HEST output file is stored on the computer from which the HEST was accessed and is available for immediate viewing and retrieval. The measure was programmed with the Catagent DreamObjects objectoriented framework (DreamLight Incorporated, Woburn, MA, USA) in Macromedia Director MX software version 10.1 (Macromedia Incorporated, Redwood City, CA, USA).

\section{HEST sequence}

After logging in, first-time users complete the HEST tutorial. Thereafter, they are presented with five screens for recording fruit, vegetables and juices they had at their previous meal. On the first screen, users identify the food type (i.e. fruit, vegetable or juice) for which that entry will be made. On the second screen, users view digital images of items in the selected food group (Fig. 1). The images are arranged alphabetically and labelled with corresponding text; a recording of the item's name plays when the cursor is rolled over the image. Users choose the item by clicking on its picture.

The third screen depicts the selected item prepared in a variety of ways. Foods are shown as prepared in 5 A Day educational materials (i.e. as whole foods; raw, cooked, canned or frozen fruit or vegetables; cut-up fruit; cooked or canned beans and peas; raw leafy vegetables; and dried fruit $)^{(8)}$. Juices are depicted according to the types of containers in which they might be served (i.e. in a bottle, carton, can, box or glass). Users click on the picture depicting the preparation method of the food or the way the juice was served.

The fourth screen depicts a life-sized image of a 1 -serving unit of the item, presented as indicated on the previous screen (Fig. 2). To ensure that the image is the correct size on monitors of different sizes, each time users log on, the HEST program changes the screen resolution 


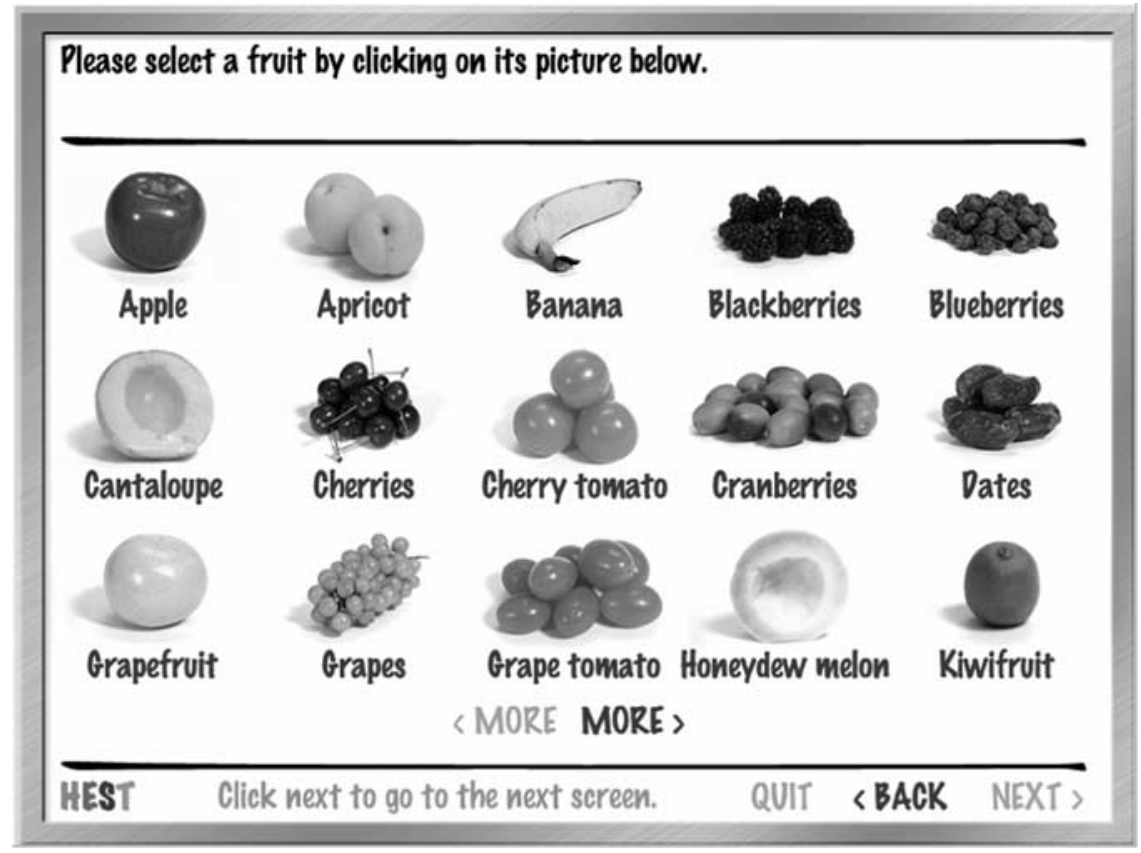

Fig. 1 Healthy Eating Self-Monitoring Tool: food selection screen for fruit

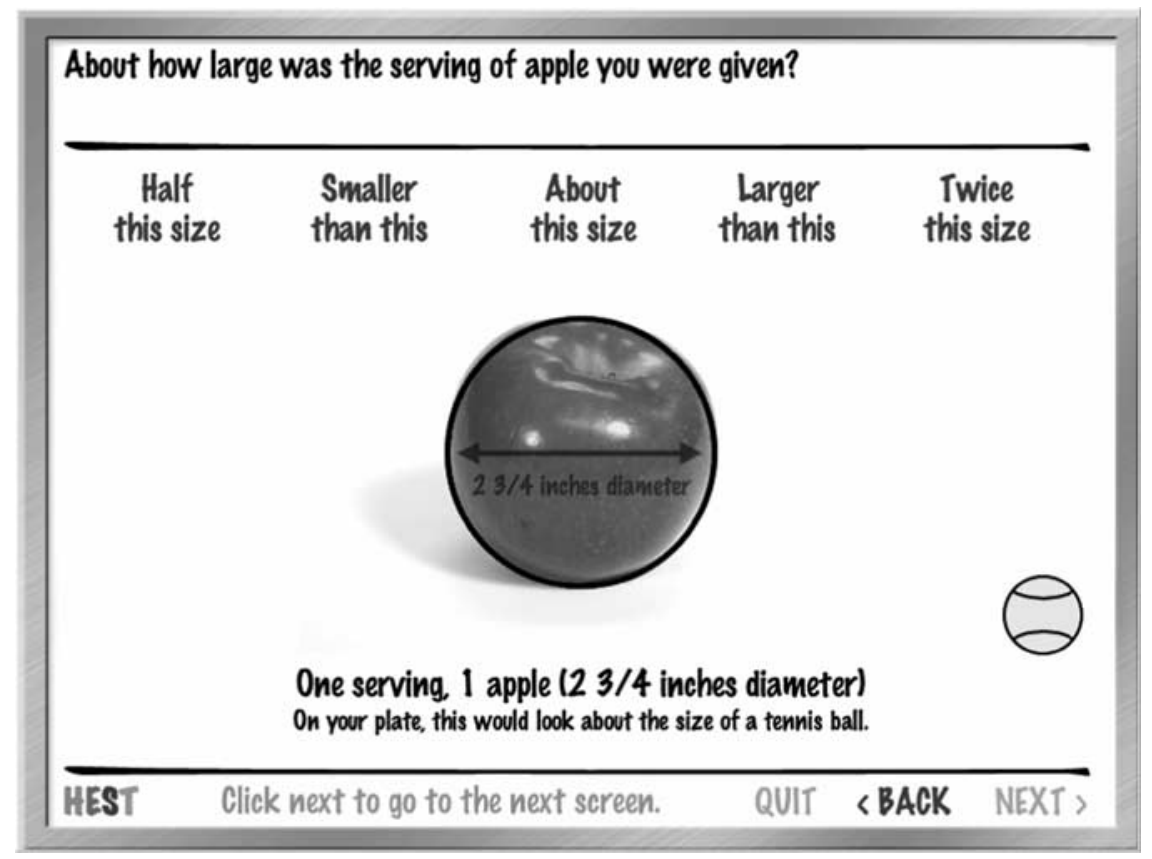

Fig. 2 Healthy Eating Self-Monitoring Tool: serving size screen for apple served whole

of the monitor attached to the computer from which the HEST is accessed to a predetermined setting. Users indicate whether the portion they were served was about the size shown, larger or smaller. They can view smaller and larger images of the item by rolling the cursor over the response options shown; the 1-serving unit image grows and shrinks accordingly. To aid users in making their selections, icons of the portion size estimation aids (PSEA) presented in the HEST tutorial are displayed on the screen. Users indicate the portion size of the food or juice they had by clicking on the picture that best represents this amount. The HEST stores a numeric value in the output file that expresses the selected portion size in relation to a 1-serving unit. Response options and their 


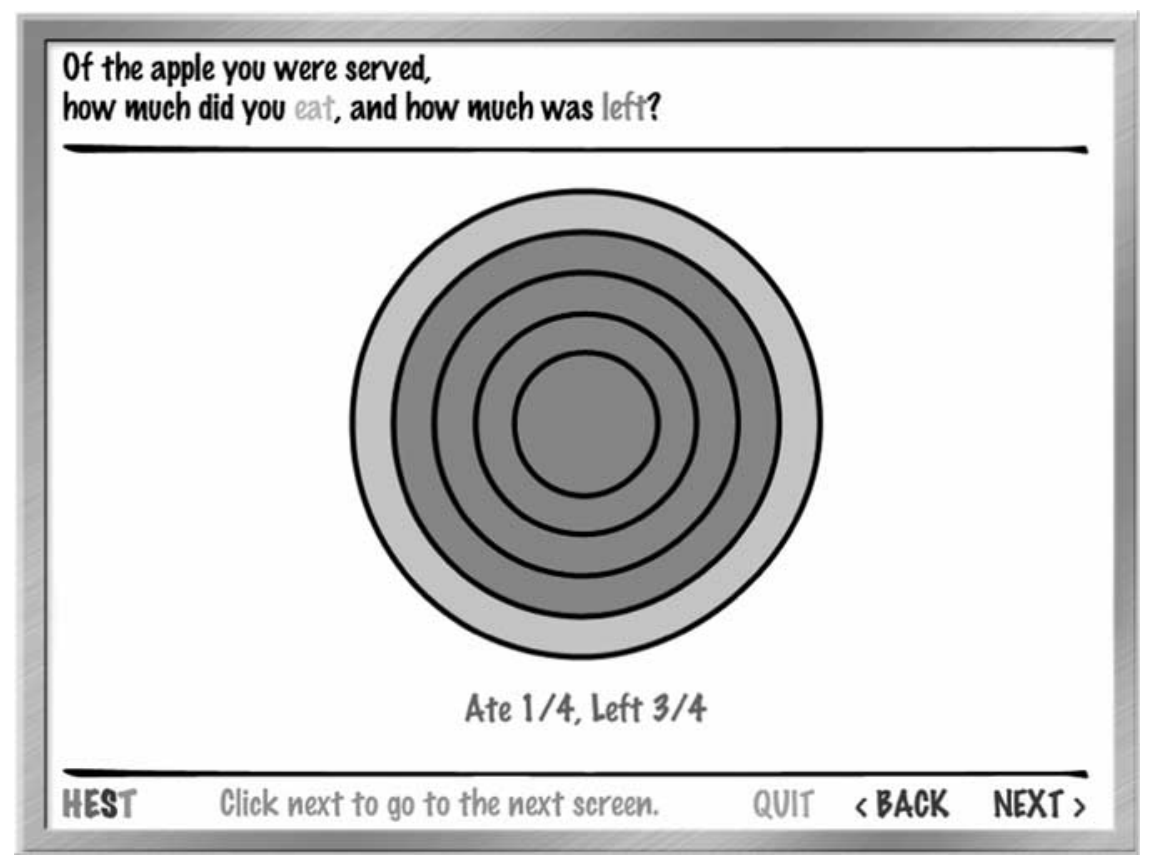

Fig. 3 Healthy Eating Self-Monitoring Tool: amount consumed screen for apple served whole

numeric equivalents are 'about this size' $(1 \cdot 0)$, 'smaller than this' $(0 \cdot 75)$, 'half this size; $(0 \cdot 50)$, 'larger than this' $(1 \cdot 5)$ and 'twice this size' $(2 \cdot 0)$.

The final screen depicts an outline of the item selected on the preceding screen. Users highlight the proportion consumed and left of the food or juice by rolling the cursor over the image (Fig. 3). They then finalize their selection by clicking on the image that represents that amount. The HEST stores a numeric value in the output file that reflects the amount consumed of the item (i.e. $0,0 \cdot 25,0 \cdot 5,0 \cdot 75$ or 1). After completing their entries for the item, the program prompts the user to enter another fruit, juice or vegetable or to exit from the program. The program calculates intake servings as the product of the recorded portion size and consumption amount of the food or juice, and stores this information in the HEST output file.

Although the HEST includes a variety of fruit, vegetables and juices, the measure is not exhaustive. Foods and juices were selected to reflect items that are commonly available throughout the year. The HEST includes a write-in option for recording intake of items that are not represented in the measure. Users selecting the write-in option complete the same screens for indicating intake that are provided for included foods and juices. They identify the food type (fruit, vegetable or juice) on the first screen. On the second screen, they type the name of the item. On the third screen, they indicate how the item was prepared by selecting from digital images of other fruit, vegetables or juices depicted according to a variety of preparation methods. Next, users view the image selected on the preceding screen and indicate the size of their food or juice portion in relation to the image shown. On the final screen, they view an outline of the selected image and highlight the proportion consumed and left of the food or juice. Write-in entries are stored in the HEST output file.

\section{Statistical analyses}

For each of the twenty-seven items studied, HEST-recorded intake entries were matched with records of observed intake. Records of HEST-recorded intake were assigned a value of zero for participants who did not record the item using the HEST. Records of observed intake were assigned a value of zero for participants who did not consume the item. Thus, non-reports of items eaten and reports of items not eaten were included in analyses.

Item analyses were performed to determine whether the accuracy of youths' recording varied based on the foods and juices measured. We also examined whether the accuracy of youths' HEST-recorded intake estimates varied by food type (i.e. fruit, vegetables, juices). As an overall indicator of the validity of the HEST for estimating fruit and vegetable consumption, observed and HESTrecorded daily and total (3 d) fruit and vegetable intake were also compared. Spearman correlations were calculated to provide an index of the relationship between rank-ordered measures of observed and HEST-recorded intake. Wilcoxon signed ranks tests were used to determine whether measures of observed and HEST-recorded intakes differed significantly.

To determine sources of error in recording, the frequency of agreement between observed and HESTrecorded item intakes was examined. Matched records of observed and HEST-recorded intakes were classified as 
agreements for respondents who both consumed and correctly recorded their item intake, and for youths who neither consumed nor recorded items. We determined sources of error in recording using records for which there was a lack of agreement. Non-reports of items eaten were classified as omissions. Reports of items not eaten were classified as intrusions. Because the HEST calculates intake servings based on HEST screen entries for recording item serving sizes and consumption amounts, we determined the extent to which intake differences were due to incorrect entries on one or both of these screens. If the respondent misestimated the portion size of the food or juice but correctly identified the consumption amount of the item, the record was classified as a portion size error (PS). If the respondent correctly estimated the portion size of the food or juice, but indicated that they consumed more or less than was observed, the record was classified as a consumption amount error (CA). If the respondent incorrectly estimated both the portion size and consumption amount of the food or juice, the record was classified as a portion size and consumption amount error (PSCA). Frequency distributions were used to examine the percentages of records in each category.

Item analyses and frequency distributions for determining sources of error in recording were repeated using data provided by youths who both consumed and recorded their consumption of individual foods and juices. The aim was to determine whether consumers recorded their item intakes more accurately than the total sample of youths. Because this approach eliminated errors of omission and intrusion, we examined the extent to which observed intake differences were attributable to the remaining error sources (i.e. PS, CA and PSCA).

Descriptive statistics examined user acceptability ratings of the HEST. A mean rating at or above $4 \cdot 0$ was the criterion for determining favourable endorsements of the HEST. All analyses were performed using the Statistical Package for the Social Sciences statistical software package version $12 \cdot 0 \cdot 1$ for Windows (SPSS Inc., Chicago, IL, USA). Values were considered significant at $P<0 \cdot 05$.

\section{Results}

Of the eighty-nine adolescents who completed the HEST following breakfast, lunch and dinner on the first day, fifty-six (63\%) did so on the second day and twenty-six ( $46 \%)$ of these youths did so on the third day. This represented a loss of an average of three participants per site on the second and third days. Two factors accounted for this. First, youths' attendance at camp programmes was sporadic; some did not complete scheduled assessments because they were absent. Second, youths were aware that their study participation was voluntary and could be discontinued at any time without penalty. These youths were present at camp but elected to participate in regularly scheduled activities rather than continue their study involvement.

Correlations between observed and HEST-recorded intake were significant for eighteen of the twenty-seven items studied, and ranged from 0.31 to $0 \cdot 81$. Wilcoxon signed ranks tests revealed non-significant intake differences for fourteen (78\%) of these items. HEST-recorded intake of artichoke hearts measured using the write-in option did not differ significantly from observed intake of this item. Examination of items for which significant intake differences were found revealed that underestimation of intake ( $83 \%$ of misestimated items) was more common than overestimation (17\% of misestimated items). Respondents overestimated their intake of apples on the first day by $0 \cdot 14$ of a serving $(P<0 \cdot 01)$. Intrusions accounted for the greatest proportion of error between observed and HEST-recorded apple intake. Youths underestimated their intake of orange, apple and grape juice on the first day by $0 \cdot 13(P<0 \cdot 01), 0 \cdot 22(P<0 \cdot 001)$ and $0 \cdot 20(P<0 \cdot 001)$ of a serving, respectively, and their intake of apple juice and $100 \%$ juice blend by a similar amount $-0 \cdot 11$ of a serving - on the second day $(P<0 \cdot 05$ and $P<0 \cdot 01$, respectively). Portion size misestimation accounted for the greatest proportion of error between observed and HEST-recorded intakes of these juices. Findings from analyses comparing observed and HESTrecorded item intakes and sources of error between these intake measures are shown in Table 1.

Analyses of data provided by youths who both consumed and recorded their consumption of foods and juices revealed that consumers also underestimated their intake of juices (data not shown). However, fewer intake differences were found. Consumers underestimated their intake of grape juice on the first day, of $100 \%$ juice blend on the second day, and of apple juice on the first and third days. Consumers also overestimated their apple intake on the first day. A difference with findings from analyses of data provided by all youths was that consumers overestimated their intake of blueberries on the first day, corn on the second and third days, and salad on the third day. Portion size misestimation was the most frequent source of the discrepancy between observed and HEST-recorded intakes of these items.

As shown in Table 2, significant correlations were found between observed and HEST-recorded daily intake of fruit on the first and third days. For vegetables and juices, significant correlations were found between observed and HEST-recorded daily intakes on the first and second days. Correlations ranged from 0.32 to 0.61 and were significant at the $0 \cdot 01$ level. Wilcoxon signed ranks tests revealed non-significant differences between these intake measures (excluding juices). Youths underestimated their daily juice intake by 0.54 of a serving $(P<0.001)$ on the first day and by 0.33 of a serving $(P<0 \cdot 01)$ on the second day. 
Table 1 Comparison of observed and HEST-recorded item intakes and sources of measurement error

\begin{tabular}{|c|c|c|c|c|c|c|c|c|c|c|}
\hline \multirow[b]{2}{*}{ Day/food item } & \multirow[b]{2}{*}{ Spearman correlation } & \multirow[b]{2}{*}{ Mean observed } & \multirow[b]{2}{*}{ Mean recorded } & \multirow[b]{2}{*}{ Wilcoxon signed ranks test } & \multirow[b]{2}{*}{$\%$ agreement } & \multicolumn{5}{|c|}{ Sources of measurement error (\%) } \\
\hline & & & & & & Omissions & Intrusions & PSt & $\mathrm{CA} \ddagger$ & PSCA $\S$ \\
\hline \multicolumn{11}{|l|}{ Day $1(n 89)$} \\
\hline \multicolumn{11}{|l|}{ Fruit } \\
\hline Blueberries & $0 \cdot 33^{\star \star}$ & 0.38 & 0.41 & NS & 33 & 20 & 17 & 10 & 11 & 9 \\
\hline Apple & $0 \cdot 43^{\star \star}$ & 0.34 & 0.48 & 0.01 & 35 & 7 & 23 & 10 & 22 & 3 \\
\hline Banana & $0 \cdot 49^{\star \star}$ & 0.63 & 0.62 & NS & 59 & 11 & 9 & 12 & 7 & 2 \\
\hline Grape tomatoes & $0.53^{\star \star}$ & 0.25 & 0.22 & NS & 62 & 14 & 10 & 4 & 4 & 6 \\
\hline \multicolumn{11}{|l|}{ Vegetables } \\
\hline Carrots & $0 \cdot 65^{\star \star}$ & 0.33 & 0.34 & NS & 48 & 5 & 16 & 9 & 11 & 11 \\
\hline Corn & $0 \cdot 46^{\star \star}$ & 0.65 & 0.59 & NS & 47 & 16 & 8 & 15 & 10 & 4 \\
\hline \multicolumn{11}{|l|}{ Juices } \\
\hline Orange & $0 \cdot 42^{\star \star}$ & 0.72 & 0.59 & $0 \cdot 01$ & 47 & 14 & 7 & 25 & 3 & 4 \\
\hline Apple & $0 \cdot 14^{\star \star}$ & 0.96 & 0.74 & 0.001 & 53 & 16 & 2 & 26 & 3 & - \\
\hline Grape & $0 \cdot 14^{\star \star}$ & 0.92 & 0.72 & 0.001 & 42 & 11 & 3 & 28 & 10 & 6 \\
\hline \multicolumn{11}{|l|}{ Day $2(n 56)$} \\
\hline \multicolumn{11}{|l|}{ Fruit } \\
\hline Peach & $0 \cdot 56^{\star \star}$ & 0.38 & $0 \cdot 30$ & NS & 54 & 14 & 2 & 4 & 21 & 5 \\
\hline Grapes & $0 \cdot 14^{\star \star}$ & 0.94 & 0.82 & NS & 50 & 14 & - & 21 & 11 & 4 \\
\hline Apple & $0.57^{\star \star}$ & 0.34 & 0.43 & NS & 61 & 7 & 11 & 2 & 14 & 5 \\
\hline \multicolumn{11}{|l|}{ Vegetables } \\
\hline Artichoke hearts & $0 \cdot 10^{\star \star}$ & $0 \cdot 10$ & 0.12 & NS & 68 & 13 & 16 & 2 & - & 1 \\
\hline Leafy salad & $0 \cdot 33^{\star \star}$ & 0.42 & 0.40 & NS & 41 & 21 & 11 & 9 & 9 & 9 \\
\hline \multirow{2}{*}{\multicolumn{11}{|c|}{ Juices }} \\
\hline & & & & & & & & & & \\
\hline Apple & $0 \cdot 42^{\star \star}$ & $0 \cdot 87$ & 0.76 & 0.05 & 63 & 7 & 2 & 20 & 7 & 1 \\
\hline Juice blend & $0 \cdot 31^{\star \star}$ & 0.98 & 0.87 & 0.01 & 66 & 4 & - & 28 & 1 & 1 \\
\hline Juice blend & $0 \cdot 31^{\star \star}$ & 0.92 & 0.81 & NS & 63 & 9 & 4 & 18 & 5 & 1 \\
\hline \multicolumn{11}{|l|}{ Day $3(n 26)$} \\
\hline \multicolumn{11}{|l|}{ Fruit } \\
\hline Banana & $0.51^{\star \star}$ & 0.49 & 0.44 & NS & 69 & 15 & 4 & 4 & 8 & - \\
\hline Cantaloupe & $0 \cdot 60^{\star \star}$ & 0.58 & 0.49 & NS & 54 & 12 & 4 & 4 & 19 & 7 \\
\hline Apple & $0 \cdot 81^{\star \star}$ & $0 \cdot 13$ & 0.17 & NS & 92 & - & 8 & - & - & - \\
\hline \multicolumn{11}{|l|}{ Vegetables } \\
\hline Celery & $0 \cdot 28^{\star \star}$ & $0 \cdot 10$ & 0.09 & NS & 73 & 12 & 12 & - & 3 & - \\
\hline Leafy salad & $0 \cdot 26^{\star \star}$ & 0.41 & 0.38 & NS & 42 & 27 & 12 & 8 & 11 & _- \\
\hline Corn & $0 \cdot 21^{\star \star}$ & 0.57 & 0.67 & NS & 39 & 19 & 8 & 15 & 15 & 4 \\
\hline \multicolumn{11}{|l|}{ Juices } \\
\hline Orange & $0 \cdot 40^{\star \star}$ & 0.63 & 0.69 & NS & 46 & 8 & 19 & 15 & 12 & - \\
\hline Apple & $0.21^{\star \star}$ & 0.92 & 0.87 & NS & 73 & 4 & 4 & 19 & - & - \\
\hline Pineapple & $0 \cdot 24^{\star \star}$ & 0.91 & 0.92 & NS & 50 & 4 & - & 23 & 23 & - \\
\hline \multicolumn{11}{|c|}{$\begin{array}{l}\text { HEST, Healthy Eating Self-Monitoring Tool. } \\
\text { Significant correlation: }{ }^{\star} P<0 \cdot 05,{ }^{\star *} P<0 \cdot 01,{ }^{\star \star \star} P<0.001 \text { (NS, } P>0.05 \text { ). } \\
\text { tError attributable to portion size misestimation. } \\
\text { tError attributable to consumption amount misestimation. } \\
\text { SError attributable to both portion size and consumption amount misestimation. }\end{array}$} \\
\hline
\end{tabular}


Table 2 Comparison of observed and HEST-recorded daily and total ( $3 \mathrm{~d})$ intake

\begin{tabular}{|c|c|c|c|c|}
\hline Interval/food type & Mean observed & Mean recorded & Spearman correlation & Wilcoxon signed ranks test \\
\hline \multicolumn{5}{|l|}{ Day 1 ( $n$ 89) } \\
\hline Fruit & $1 \cdot 34$ & $1 \cdot 51$ & $0 \cdot 45^{\star *}$ & NS \\
\hline Vegetables & $1 \cdot 23$ & $1 \cdot 16$ & $0.61^{\star *}$ & NS \\
\hline Juices & 2.59 & $2 \cdot 05$ & $0.32^{* *}$ & 0.001 \\
\hline Fruit and vegetable intake & $5 \cdot 16$ & $4 \cdot 71$ & $0.49^{\star *}$ & 0.05 \\
\hline \multicolumn{5}{|l|}{ Day $2(n 56)$} \\
\hline Fruit & $1 \cdot 67$ & 1.56 & $0 \cdot 24^{\star \star}$ & NS \\
\hline Vegetables & $1 \cdot 15$ & $1 \cdot 14$ & $0 \cdot 40^{* *}$ & NS \\
\hline Juices & $2 \cdot 77$ & $2 \cdot 44$ & $0 \cdot 34^{\star *}$ & 0.01 \\
\hline Fruit and vegetable intake & $5 \cdot 58$ & $5 \cdot 15$ & $0 \cdot 38^{* *}$ & NS \\
\hline \multicolumn{5}{|l|}{ Day $3(n 26)$} \\
\hline Fruit & $1 \cdot 19$ & $1 \cdot 10$ & $0.56^{\star \star}$ & NS \\
\hline Vegetables & 1.08 & $1 \cdot 14$ & $0.32^{\star \star}$ & NS \\
\hline Juices & $2 \cdot 47$ & $2 \cdot 48$ & $0 \cdot 25^{\star \star}$ & NS \\
\hline Fruit and vegetable intake & $4 \cdot 74$ & $4 \cdot 73$ & $0.52^{\star *}$ & NS \\
\hline \multicolumn{5}{|l|}{ Total $(3 \mathrm{~d})$ intake $(n 26)$} \\
\hline Fruit & $3 \cdot 84$ & $4 \cdot 21$ & $0.39^{\star \star}$ & NS \\
\hline Vegetables & $3 \cdot 29$ & $3 \cdot 32$ & $0.58^{\star \star}$ & NS \\
\hline Juices & 8.09 & $7 \cdot 12$ & $0 \cdot 28^{\star \star}$ & 0.05 \\
\hline Fruit and vegetable intake & $15 \cdot 21$ & 14.65 & $0.46^{\star *}$ & NS \\
\hline
\end{tabular}

HEST, Healthy Eating Self-Monitoring Tool.

Significant correlation: ${ }^{\star} P<0.05,{ }^{\star \star} P<0.01,{ }^{\star \star \star} P<0.001$ (NS, $P>0.05$ ).

HEST-recorded daily fruit and vegetable intake was significantly correlated with observed daily fruit and vegetable intake on each day. Correlations ranged from 0.38 to 0.52 and were significant at the $0 \cdot 01$ level. Nonsignificant differences were found between these intake measures on the second and third days. HEST-recorded $3 \mathrm{~d}$ intake of 14.65 servings was significantly correlated with observed $3 \mathrm{~d}$ intake of $15 \cdot 21$ servings $(\rho=0 \cdot 46$, $P<0 \cdot 05)$, and there were non-significant differences between these intake measures. Mean (SD) ratings of youths' enjoyment of, interest in and likelihood of recommending the HEST to peers were $4 \cdot 50(0 \cdot 86), 4 \cdot 38$ $(0 \cdot 64)$ and $4 \cdot 12(0 \cdot 86)$, respectively. These values were above the user acceptability criterion rating.

\section{Discussion}

Observed and HEST-recorded item intakes were significantly correlated for most $(67 \%)$ foods and juices studied $(\rho$ range $=0 \cdot 31-0 \cdot 81$ ). Findings from correlation analyses were corroborated by findings from Wilcoxon signed ranks tests, which revealed the absence of significant intake differences among $78 \%$ of these items. Youths accurately recorded their daily intake of fruit and vegetables; however, they underestimated their daily juice intake on the first and second days, and underestimated their total (3 d) juice intake. Although youths underestimated their daily fruit and vegetable intake on the first day, the accuracy of their reporting increased over time. Observed daily fruit and vegetable intake was significantly correlated with HEST-recorded daily fruit and vegetable intake on the second and third days $(\rho=0.38$ and $\rho=0.52, P<0 \cdot 01)$. Moreover, there were few significant differences between these intake measures on both days. The significant correlation between youths' observed and HEST-recorded $3 \mathrm{~d}$ intake and the absence of differences between these intake measures support the criterion validity of the HEST.

Prior studies examining the performance of computermediated intake assessment measures have focused on nutrient intakes $v$. food intakes ${ }^{(9-13)}$. Furthermore, most studies have validated computer-mediated food frequency and $24 \mathrm{~h}$ recall measures, thus making comparisons between findings from the present study and findings from previous studies difficult ${ }^{(11-13)}$. Across studies, the overestimation of nutrient intakes was more common than underestimation. In one study examining the performance of a computer-mediated food record relative to intake measured via a $24 \mathrm{~h}$ recall, no significant differences were found between daily intake measures of energy and macronutrients ${ }^{(9)}$. In another study, individuals significantly overestimated their daily intakes of $\mathrm{Zn}$, Mn, vitamin E, SFA, PUFA and fibre measured via a food record delivered on a personal digital assistant (PDA) with camera and mobile telephone card relative to intake measured via $1 \mathrm{~d}$ weighed food records and a $24 \mathrm{~h}$ recall $^{(10)}$. Thus, conclusions regarding whether youths' underestimation of intake is unique to this study or a common occurrence when intakes are measured using computer-mediated food records must await further research.

Portion size misestimation was the most frequent source of error between observed and HEST-recorded item intakes. Findings for the total sample of youths were similar to findings based on data provided by consumers. HEST users estimated their food and juice portions relative to an image of a 1-serving unit of the item prepared 
as indicated on the previous HEST screen. The HEST approach for gathering portion size data is similar to the approach described in studies that have used twodimensional PSEA to gather this information ${ }^{(14,15)}$. This approach may account for observed portion size misestimation rates. Godwin et al. found misestimation of foods (i.e. beef, ice cream, macaroni \& cheese) to be increased (i.e. over the mean misestimation rate of $\pm 20 \%)$ when two-dimensional aids were used instead of three-dimensional ones ${ }^{(14)}$.

A study comparing the accuracy of nutrient intakes measured via a food record delivered on a PDA and $24 \mathrm{~h}$ recall found portion size estimation error to be the greatest source of error between measurement methods $^{(9)}$. A $50 \%$ error rate occurred despite training in portion size estimation and practice in advance of recording for $3 \mathrm{~d}$. In our study, the training received by participants was limited to that provided in the HEST tutorial. The short duration of the training and the absence of opportunities for practice may not have sufficiently prepared youths to accurately estimate their food and juice portions using the HEST.

Rates of omission observed in the present study were similar to rates reported in a study comparing food and beverage intakes measured via a computer-mediated $24 \mathrm{~h}$ recall with $1 \mathrm{~d}$ food records ${ }^{(11)}$, whereas observed rates of intrusion were slightly higher than in that study. In Vereecken et al.'s ${ }^{(11)}$ study, omissions ranged from $0 \%$ for diet soft drinks to $28 \%$ for sauces and butter; intrusions varied from $0 \%$ for fish and bread to $18 \%$ for fruit. We found rates of omission ranging from $0 \%$ for apple to $27 \%$ for leafy salad; intrusions ranged from $0 \%$ for pineapple juice, $100 \%$ juice blend and grapes to $23 \%$ for apple. Features of the measure described by Vereecken et $a l .{ }^{(11)}$ may account for this difference. Following meal entries, the computer-mediated recall required respondents to confirm that their entries were complete. A check performed by the program determined whether the respondent had entered a beverage for that meal; if not, he or she was given the opportunity to modify his or her entries. When entries for an entire day were completed, youths were required to review and confirm all entries for that day. The HEST, on the other hand, did not require users to review their intake entries. Thus, they were not able to confirm that all foods and juices consumed at meals were recorded.

Mean ratings of the extent to which youths found the HEST interesting, enjoyable and worth recommending to peers were above the criterion rating, an indication that youths universally endorsed the HEST. This result is promising, given that youths were fairly accurate in recording their intake using the HEST and found the measure acceptable.

The use of a small and self-selected sample limits the generalizability of study findings. Adolescents who elected to enrol in the study may differ from adolescents attending summer camp programmes offered in similar settings. Moreover, user acceptability ratings of the HEST and findings regarding youths' total intake may be biased because they were based on data provided by the twentysix youths who completed the $3 \mathrm{~d}$ study protocol. Youths who completed the protocol may have been more motivated to do so than those who did not. Respondents did not have the option of selecting from among a variety of fruit, vegetables and juices at meals; thus, it is unknown whether observed intake accurately reflects respondents' eating behaviours. The inter-observer reliability of observational data used to validate the HEST could not be determined because there was only a single observer at meals.

Additional research is needed to determine whether repeated exposure to the HEST tutorial improves youths' ability to estimate their food and juice portions. The absence of improvement would implicate the need to refine the HEST approach for gathering portion size data. Possibly, the approach can be enhanced by including images that more closely approximate three-dimensional objects; for example, by depicting food and juice portions viewed from multiple perspectives (i.e. top down, side view, front view).

Moreover, it is necessary to examine whether the inclusion of system checks that allow users to review and edit their meal intake entries would reduce errors of omission and intrusion, thereby improving the accuracy of the HEST.

Findings add to the limited data on the validity and user acceptability of computer-mediated food record approaches. Youths' total HEST-recorded intake was accurate to within approximately one half of a serving of their observed intake. Youths' favourable endorsements of the HEST suggest that it may be preferable to conventional paper-and-pencil food record approaches. The HEST is a portable and cost-effective alternative to these approaches.

\section{Acknowledgements}

We certify that there are no affiliations with or financial involvement in any organization or entity with a direct financial interest in the subject matter or materials discussed in this manuscript. The work under consideration was supported by funding from the National Cancer Institute (grant no. CA 096162). J.D.N. designed the study, supervised all aspects of its implementation, conducted statistical analyses and wrote the paper. I.R.C. helped to conceptualize ideas, interpret findings and review drafts of the manuscript.

\section{References}

1. Rockett HRH \& Colditz GA (1997) Assessing diets of children and adolescents. Am J Clin Nutr 65, Suppl., 1116-1122. 
2. Thompson FE \& Byers T (1994) Dietary assessment resource manual. J Nutr 124, Suppl., 2245-2317.

3. Witschi JC (1990) Short-term dietary recall and recording methods. In Nutritional Epidemiology, pp. 52-67 [W Willett, editor]. New York: Oxford University Press.

4. Domel SB, Baranowski T, Leonard SB, Davis H, Riley P \& Baranowski J (1994) Accuracy of fourth- and fifth-grade students' food records compared with school lunch observations. Am J Clin Nutr 59, Suppl., 218-220.

5. Di Noia J, Contento IR \& Schinke SP (2007) Criterion validity of the Healthy Eating Self-Monitoring Tool (HEST) for black adolescents. I Am Diet Assoc 107, 321-324.

6. US Census Bureau (2005) Tracts with 20 Percent or More in Poverty by State. http://www.census.gov/hhes/ poverty/20percent/20percent.html (accessed February 2007).

7. US Department of Agriculture, Economic Research Service (2002) Plate Waste in School Nutrition Programs: Final Report to Congress. http://www.ers.usda.gov/publications/ efan02009/efan02009.pdf (accessed April 2006).

8. National Cancer Institute (undated) What is a Serving Size of Fruits and Vegetables? http://www.5aday.org/html/ consumers/serving.php (accessed April 2006).

9. Beasley J, Riley WT \& Jersino JM (2005) Accuracy of a PDAbased dietary assessment program. Nutrition 21, 672-677.
10. Wang DH, Kogashiwa M \& Shohei K (2006) Development of a new instrument for evaluating individuals' dietary intakes. J Am Diet Assoc 106, 1588-1593.

11. Vereecken CA, Covents M, Matthys C \& Maes L (2005) Young adolescents' nutrition assessment on computer (YANA-C). Eur J Clin Nutr 59, 658-667.

12. Matthys C, Pynaert I, Roe M, Fairweather-Tait SJ, Heath AL \& De Henauw S (2004) Validity and reproducibility of a computerized tool for assessing the iron, calcium, and vitamin C intake of Belgian women. Eur J Clin Nutr 58, 1297-1305.

13. Health AL, Skeaff CM \& Gibson RS (2000) The relative validity of a computerized food frequency questionnaire for estimating intake of dietary iron and its absorption modifiers. Eur J Clin Nutr 54, 592-599.

14. Godwin SL, Chambers E \& Cleveland L (2004) Accuracy of reporting dietary intake using various portion-size estimation aids in-person and via telephone. J Am Diet Assoc 104, 585-594.

15. Yaroch AL, Resnicow K, Davis M, Davis A, Smith M \& Khan LK (2000) Development of a modified picture-sort food frequency questionnaire for low-income, overweight, African-American adolescent girls. J Am Diet Assoc 100, 1050-1056. 